\title{
Finite Element Modeling and Analysis of Skin Panel Based On the Fiber Orientation and Stacking Sequence
}

\author{
Dr.R.Rajappan ${ }^{1}$, Dr.S.Sundararaj ${ }^{2}$ and V.Pugazhenthi ${ }^{3}$ \\ ${ }^{1}$ (Prof /Mech Dept, Mailam Engineering College, Mailam, Tamilnadu, India) \\ ${ }^{2}$ (Asso.prof/Mech Dept, Mailam Engineering College, Mailam, Tamilnadu, India) \\ ${ }^{3}$ (M.E Scholar, Mailam Engineering College, Mailam, Tamilnadu, India)
}

\begin{abstract}
Composite materials are ideal for structural application where high strength-to-weight and high stiffness-to-weight ratios are required. In particular, Aircraft and Spacecraft are the typical weight-sensitive structures in which composite material are cost-effective. A major purpose of lamination is to tailor the directional dependence of strength and stiffness of a composite material to match the loading environment on the structural element. Since the fiber orientation enables the optimization of the mechanical behavior along a specific direction, the study has been made to analyze the behavior of the laminate properties and strength based on the fiber orientation.
\end{abstract}

Keywords: fiber orientation, hyper mesh, laminated, stacking sequence, wing skin.

\section{Introduction}

Composite materials can be tailored to meet the specific needs of strength and stiffness requirements, and as such these materials have been well recognized for aircraft applications wherein high performance and low weight are the essential pre-requisites. The study has been made to analyze the behavior of the laminaete properties and strength varies with fiber orientation and stacking sequence.

A portion of typical wing skin has been taken as a laminaete with application of compressive load for two different cases of fiber orientation and stacking sequence. The pre and post processing has been done using the finite element software Hyper Mesh and solver MSC/NASTRAN.

\subsection{COMPOSITES}

Fiber reinforced composite material consists of fibers of high strength and modulus embedded in or bonded to a matrix with distinct interface between them. In this form, both fibers and matrix retain their physical and chemical identities, yet they produce a combination of properties that cannot be achieved with either of the constituent acting alone.

In general, fibers are the principal load-carrying members, while the surrounding matrix keeps them in the desired locations and orientation, acts as a load transfer medium between them, and protects them from environmental damages due to elevated temperatures and humidity. The most common form in which fiber reinforced composites are used in structural applications is called a laminaete. It is obtained by stacking a number of thin layers of fibers and matrix and consolidating them in to the desired thickness.

Fiber orientation in each layer as well as stacking sequence of various layers can be controlled to generate a wide range of physical and mechanical properties for the composite laminaetes. The properties that can be emphasized by laminaetion are strength, stiffness, low weight, corrosion resistance, wear resistance, attractiveness, thermal insulation, acoustical insulation, etc. Examples of laminaeted fiber reinforced composites include Missile cases, Fiber glass boat hulls, Aircraft wing panels and body sections, Tennis rackets, Golf club shafts, etc

\subsubsection{COMPOSITE MATERIALS}

A composite material may consist of many materials put together in many different ways. A simple example is material consisting of two phases. The matrix phase is continuous and forms the shape in which the dispersed phase acts as a constituent. There are different types of dispersed phase. It can be of a particle nature, meaning each particle is equaled, or it can be of a fibrous nature, where the dispersed phase is a filament. The type of dispersed phase, its orientation (for the fibrous type), size, relative amounts, and material properties will all affect the properties of the overall material.

\subsubsection{FIBER REINFORCEMENTS}

Fiber reinforced polymer matrix composites have fibers that are continuous or discontinuous, and they are typically circular and vary in diameter from $0.1 \mathrm{~mm}$ to $0.1 \mathrm{~mm}$ as indicated by Stefanescu. Fiber loading, which is the fiber content of the composite, usually is in the range of 20 to $80 \%$ by volume. Optimal load 
transfer from the matrix to the fibers occurs when fibers are continuous. This is due to the fact that the ends of the fibers do not exercise $100 \%$ stress support leading to what is known as an "end effect" for the fiber. However, the discontinuous fibers usually have an aspect ratio that is high enough to limit the end effect to a very small or even negligible factor.

\subsubsection{THE MATRIX PHASE:}

The matrix phase is an essential part of the composite composition. Matrix materials can consist of a metal, polymer or a ceramic. Polymer matrices are the most common followed by metal and ceramics. The matrix phase has several important functions with respect to fibrous reinforced composites. The matrix acts to hold all reinforcements together thereby allowing the applied force to transmit to the reinforcement. The matrix, due to its inherent ductility, does not carry a significant portion of the applied load. Instead the load is transmitted to the fibers. In order for this to occur the composite constituents must have a high fiber to matrix strength ratio. This can be seen in Figure below.

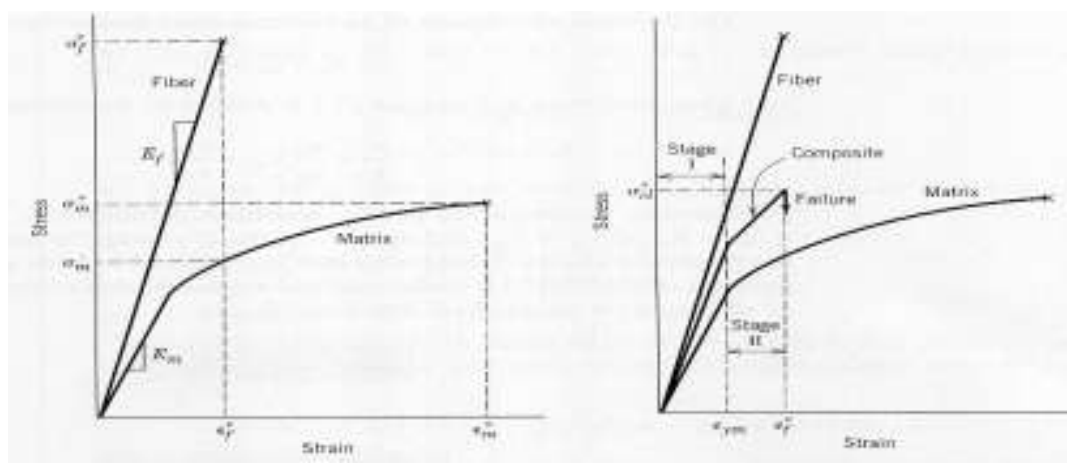

Fig 1.1: Stress -Strain curves of composite constituents

\subsubsection{COMPOSITE PROPERTIES}

The final properties of a composite are determined by fiber content, matrix material, fiber material, fiber orientation, and to a smaller extent by the fiber length and distribution in the composite. The reinforcing effects of the fiber in the composite are best explained by the rule of mixtures. In this rule, the properties of the composite depend directly on the volume fractions of each component in the mixture and the respective properties of the fiber and the matrix.

$$
\sigma_{\mathrm{c}=} \sigma_{\mathrm{f}} \mathrm{V}_{\mathrm{f}}+\sigma_{\mathrm{m}} \mathrm{V}_{\mathrm{m}} \text { and } \mathrm{E}_{\mathrm{c}}=\mathrm{E}_{\mathrm{f}} \mathrm{V}_{\mathrm{f}}+\mathrm{E}_{\mathrm{m}} \mathrm{V}_{\mathrm{m}}
$$

Where $\sigma=$ Strength of the material, $\mathrm{V}=$ Volume fraction of component, $\mathrm{E}=$ Modulus of elasticity of the material. The subscripts $\mathrm{c}$ is for the finished composite, $\mathrm{f}$ is for the fiber, and $\mathrm{m}$ is for the matrix.

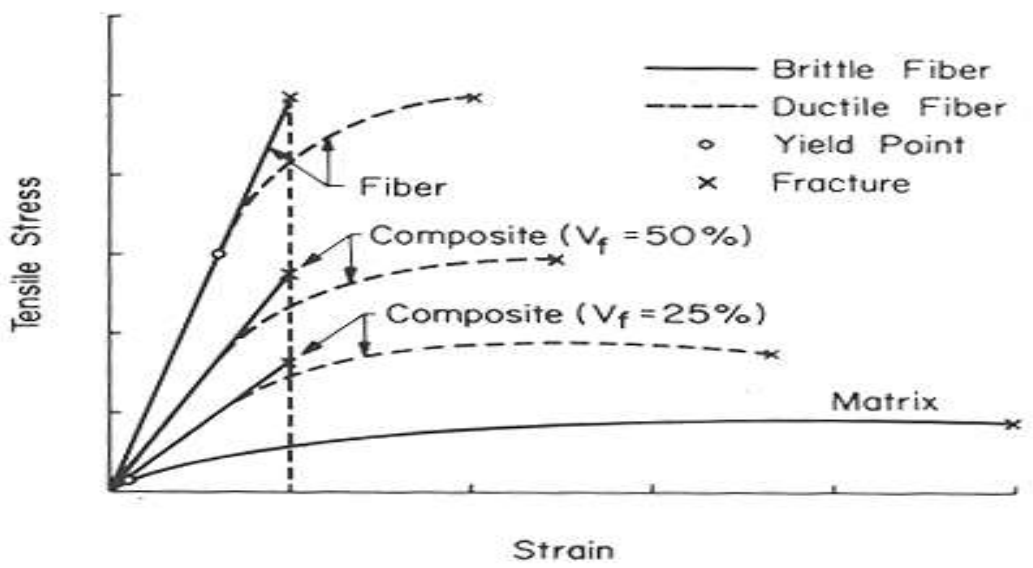

Fig 1.2 Properties of the composite based on the properties of the Component materials

\subsubsection{DEPENDENCE OF PROPERTIES BASED ON FIBER AND LOADING STRESS ORIENTATIONS}

The composite response with regards to fiber orientation depends on the direction of loading. As seen in figure, the composite response differs as the load is applied in different directions with respect to the fiber orientation. The unidirectional composite will have the greatest strength of all composites with a load aligned to 
the fibers. In other directions its strengths will decrease quite considerably. For the bi-directional composite, the highest strength will be lower, but it will occur in two directions. In this manner, as the direction of the fibers becomes more evenly distributed throughout the composite, the highest strength will be diminished, but the properties will become more uniform in all loading orientations.

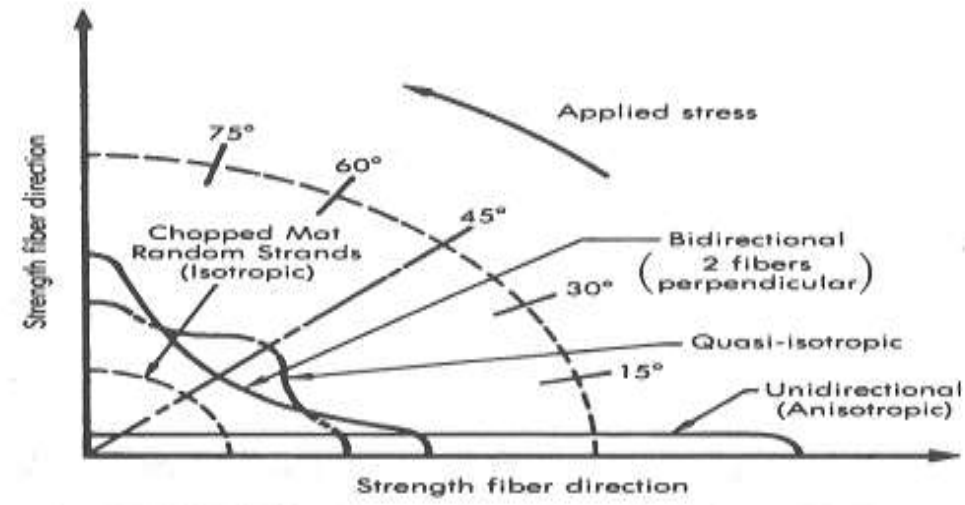

Fig1.3 Dependence of properties based on fiber and loading stress orientations

\subsubsection{TRANSFORMATION OF MATERIAL PROPERTIES (1-2 TO X-Y)}

In order to analyze laminaetes having multiple lamina with fibers in different directions, it is necessary to determine material properties in an arbitrary $\mathrm{x}-\mathrm{y}$ coordinate system in terms of material properties in the 1-2 principal material directions. This is a simple transformation similar to stress transformation done in ENGR 214 (from which Mohr's Circle is obtained).

Consider a laminae that has the principal 1 material axes at angle $\theta$ to the $\mathrm{x}$ axis (+ counterclockwise) as shown below. We can transform forces from $\mathrm{x}-\mathrm{y}$ to $1-2$ coordinates using the simple relationship:

$$
\left\{\begin{array}{l}
F_{1} \\
F_{2}
\end{array}\right\}=\left[\begin{array}{cc}
c & s \\
-s & c
\end{array}\right]\left\{\begin{array}{l}
F_{x} \\
F_{y}
\end{array}\right\}=\left[T^{*}\right]\left\{\begin{array}{l}
F_{x} \\
F_{y}
\end{array}\right\}
$$

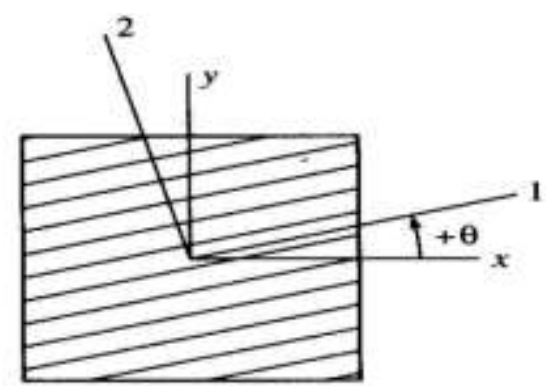

Positive $\boldsymbol{\theta}$

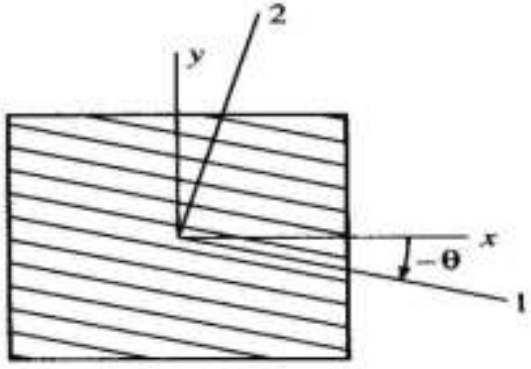

Negative $\theta$

Where

Fig 1.4 sign convention for laminae orientation.

$1 \& 2$ is the local (material) coordinate system

$\mathrm{x} \& \mathrm{y}$ is the global coordinate system

\subsubsection{CARBON FIBER-REINFORCED POLYMER COMPOSITES (CFRP):}

Carbon fiber composites are the most commonly used where advanced (non-GFRP) are Necessary. The composite material is similar in nature to the GFRP composite with the difference lying in the reinforcement material. The carbon (actually graphite at room temperature) fibers replace the glass fibers used in GFRP. Carbon fibers were chosen for advanced composite applications due to the various characteristics listed below:

1. Carbon fibers strongest of all fiber materials

2. Retain strength properties at high temps

3. Relatively inert at room temperature

4. Wide range of fiber properties - allowing engineers to better design composites

5. Relatively low cost / Easily fabricated Applications for CFRP composites are virtually unlimited and include such things as sporting equipment, bike frames and stabilizers such as helicopter rudders. 
1.1.8 COMPOSITE LAMINAETE TERMINOLOGY

One of the most common forms of fiber-reinforced composite materials is the cross plied laminaete, in which the fabricator Vlays up" a sequence of unidirectional reinforced Iplies". Each ply is typically a thin (approximately $0.2 \mathrm{~mm}$ ) sheet of collimated fibers impregnated with an uncured epoxy or other thermosetting polymer matrix material. The orientation of each ply is arbitrary, and the layup sequence is tailored to achieve the properties desired of the laminaete.

\section{$>$ Symmetric laminaete}

In Symmetric laminaete, the ply orientation is symmetrical about the centerline of the laminaete, that is, for each ply above the mid plane, there is an identical ply at an equal distance below the mid plane.

\section{$>$ Quasi- isotropic laminaetes}

These laminaetes are made of three or more laminaes of idential thickness and material with equal angles between each adjancent laminae.thus, if the total number of laminaes is $\mathrm{n}$, the result in laminaete exhibites an inplane isotropic elastic behavior in the xy plane. However,its strength properties may still vary with the direction of loading.

\section{$>$ Prepregs}

Prepregs are a ready-made tape composed of fibers in a polymer matrix. Depending on whether the polymer matrix is thermo set or thermoplastic, the tape is stored in a refrigerator or at room temperature, respectively. One can lay these tapes manually or mechanically at various orientations to make a composite structure.

\section{$>$ Stacking sequence}

The wing is assumed to consist of $n$ unstiffened composite panels. Ply Orientations are limited to $0^{\circ}$, $90^{\circ}$, and $\pm 45^{\circ}$. It is also assumed that wing depth is much greater than skin thickness, so that the stresses in the skin are influenced by the number of plies of each orientation rather than their arrangement in the stacking sequence.

Consequently, the design process will have the overall wing design determine the amount of plies of each orientation, while the panel design will determine the stacking sequence. The two design processes must be coordinated in order to assure the optimality of the process and insure that the wing design optimization takes into account the effect of its decisions on the panel design. The stacking sequence design is then limited to permutations of given plies, but not to changes in the number of plies of each orientation.

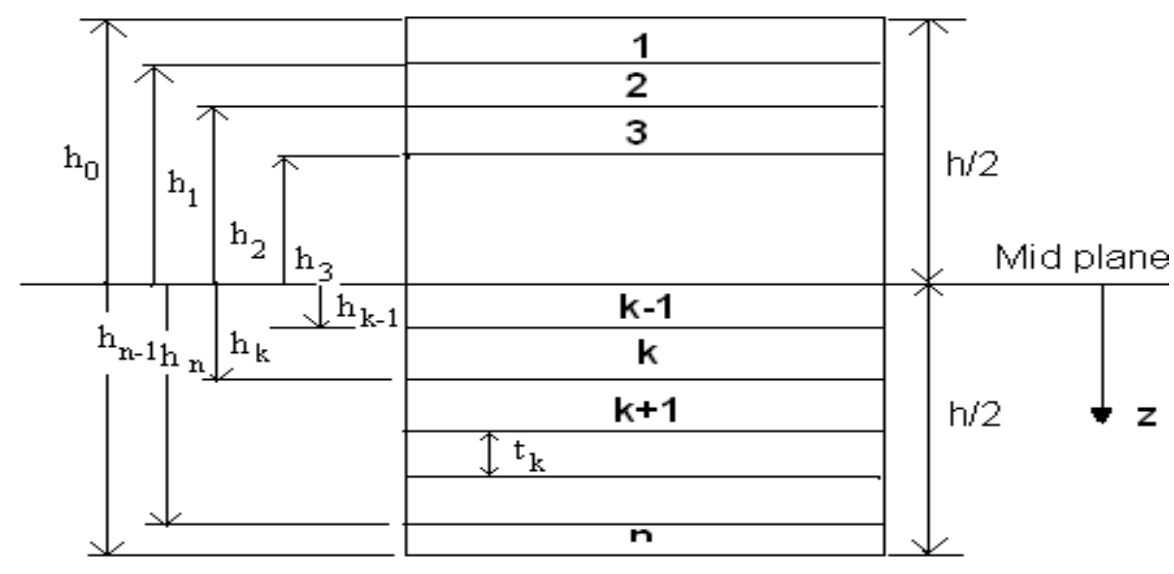

Fig1.5Laminaete geometry

\subsection{MECHANICS OF COMPOSITE MATERIAL}

1.2.1 MICROMECHANICS- The study of interaction between the fiber and matrix in a laminae such that the mechanical behavior of the laminae can be predicted from known behavior of constituents.

$>$ Establishes the relationship between the properties of the constituents (the fiber and matrix) and those of the unit composite ply.

$>$ Required to correlate with measured ply level and laminaete level tests.

$>$ It is mainly used for certain physical properties like density, fiber volume, etc.,

The basic equations used to predict the longitudinal modulus $(\mathrm{E})$, strength $(\mathrm{F})$ of the fiber reinforced composites and overall Poisson's ratio (v) are the parallel element mixtures equations. 


$$
\begin{aligned}
& E_{11}=E_{f} V_{f}+E_{m}\left(1-V_{f}\right) \\
& F_{11}=F_{f} V_{f}+F_{m}\left(1-V_{f}\right) \\
& E_{22}=1 /\left(V_{f} / E_{f}+\left(1-V_{f}\right) / E_{m}\right) \\
& G_{12}=1 /\left(V_{f} / G_{f}+\left(1-V_{f}\right) / G_{m}\right) \\
& v_{12}=v_{f} V_{f}+v_{m}\left(1-v_{f}\right)
\end{aligned}
$$

Where,

$\mathrm{E}_{11} \& \mathrm{~F}_{11}$ - Modulus of elasticity and strength parallel to fiber length

$\mathrm{E}_{22}$ - Modulus of elasticity along transverse to the fiber direction.

$\mathrm{G}_{12}$ - Shear modulus of a laminae.

$E_{f} \& F_{f}-$ Modulus of elasticity and strength of fiber.

$\mathrm{E}_{\mathrm{m}} \& \mathrm{~F}_{\mathrm{m}}$ - Modulus of elasticity and strength of matrix.

$v_{f} \& v_{m}$ - Volume of fiber and matrix.

$G_{f} \& G_{m}-$ Shear modulus of a fiber and matrix.

\subsubsection{MACRO MECHANICS-}

The study of mechanical behavior at any point in a laminaete based on the known behavior of the laminaete.

Establishes the relationship between the properties of the plies and those of resultant laminaete. Ply as homogeneous and orthotropic.

$>$ Laminaetion theory for determining the properties of the ply and laminaete.

$>\quad$ The ply properties are determined from ply level and laminaete tests.

The composite structures are more likely to in the form of laminaetes consisting of multiple laminae or ply, oriented in the desired directions and bonded together in a structural unit. The analysis of laminaete will be introduced by considering a simplified theory of laminaeted beam pure flexure.

\subsubsection{CLASSICAL LAMINAETION THEORY:}

A mathematical formulation for predicting the macro-mechanical behavior of a laminaete based on an arbitrary assembly of homogeneous orthotropic lamina. This theory enables to calculate forces moments if the strains and curvatures are known. Then the lamina stresses can be calculated from laminaete coordinates. Then the lamina stresses are transformed from laminaete coordinates to lamina principal material directions. Finally a failure criterion is applied to each laminae in its own principal material directions.

Basic assumptions:

$>\quad$ The structure is thin and combination of lamina cured and consolidated into a single plate. The through

$>\quad$ plate thickness direct stress $\left(\sigma_{z}\right)$ is zero and only plane stress $\left(\sigma_{\mathrm{xy}}\right)$ exists.

$>$ The theory is point analysis in an effectively infinitely large plate and shell completely ignoring the

$>\quad$ effects of neighboring edges and holes stiffeners, cutouts or any discontinuity.

The loading is assumed to be in-plane membrane stress and moments resultants.

\subsubsection{STIFFNESS FORMULATION PROCEDURE:}

An infinite number of possible laminaete configurations a consistent methodical approach for determining the stiffness, compliance and equivalent elastic constants values is essential. The following procedure is adopted,

i. $\quad$ For given elastic properties $E_{1}, E_{2}, G_{12}, \mathrm{v}_{12}$, to find reduced stiffness terms $Q_{11}, Q_{12}, Q_{22}, Q_{33}$ :

$$
\left[\begin{array}{c}
\sigma_{1} \\
\sigma_{2} \\
\tau_{12}
\end{array}\right]=\left[\begin{array}{ccc}
Q_{11} & Q_{12} & 0 \\
Q_{12} & Q_{22} & 0 \\
0 & 0 & Q_{33}
\end{array}\right] *\left[\begin{array}{c}
\varepsilon_{1} \\
\varepsilon_{2} \\
\gamma_{12}
\end{array}\right], \text { Where } \quad \begin{aligned}
& Q_{11}=E_{1} /\left(1-v_{12} v_{21}\right) \\
& Q_{22}=E_{2} /\left(1-v_{12} v_{21}\right) \\
& Q_{33}=G_{12} \\
& Q_{12}=v_{12} E_{2} /\left(1-v_{12} v_{21}\right)
\end{aligned}
$$

terms.

The elastic properties of the cured laminae have been used to obtain the reduced stiffness

ii. $\quad$ Calculate transformed reduced matrix $\bar{Q} i j$ for a given angle ply: 
Table 1.1 Transformed reduced matrix

\begin{tabular}{|l|l|l|l|l|}
\hline & $\mathrm{Q}_{11}$ & $\mathrm{Q}_{22}$ & $\mathrm{Q}_{12}$ & $\mathrm{Q}_{33}$ \\
\hline $\bar{Q}_{11}$ & $\mathrm{~m}^{4}$ & $\mathrm{n}^{4}$ & $2 \mathrm{~m}^{2} \mathrm{n}^{2}$ & $4 \mathrm{~m}^{2} \mathrm{n}^{2}$ \\
\hline $\bar{Q}_{22}$ & $\mathrm{n}^{4}$ & $\mathrm{~m}^{4}$ & $2 \mathrm{~m}^{2} \mathrm{n}^{2}$ & $4 \mathrm{~m}^{2} \mathrm{n}^{2}$ \\
\hline $\bar{Q}_{33}$ & $\mathrm{~m}^{2} \mathrm{n}^{2}$ & $\mathrm{~m}^{2} \mathrm{n}^{2}$ & $-2 \mathrm{~m}^{2} \mathrm{n}^{2}$ & $\left(\mathrm{n}^{2}-\mathrm{m}^{2}\right)^{2}$ \\
\hline $\bar{Q}_{12}$ & $\mathrm{~m}^{2} \mathrm{n}^{2}$ & $\mathrm{~m}^{2} \mathrm{n}^{2}$ & $\mathrm{n}^{4}+\mathrm{m}^{4}$ & $-4 \mathrm{~m}^{2} \mathrm{n}^{2}$ \\
\hline $\bar{Q}_{13}$ & $\mathrm{~m}^{3} \mathrm{n}$ & $-\mathrm{mn}^{3}$ & $\mathrm{mn}^{3}-\mathrm{m}^{3} \mathrm{n}$ & $2\left(\mathrm{mn}^{3}-\mathrm{m}^{3} \mathrm{n}\right)$ \\
\hline $\bar{Q}_{23}$ & $\mathrm{mn}^{3}$ & $-\mathrm{m}^{3} \mathrm{n}$ & $\mathrm{m}^{3} \mathrm{n}-\mathrm{mn}^{3}$ & $2\left(\mathrm{~m}^{3} \mathrm{n}-\mathrm{mn}^{3}\right)$ \\
\hline
\end{tabular}

iii. Calculate each ply thickness (t) \& centroidal (h) values associated with $B_{i j} \& D_{i j}$ :

iv. Determine the $A_{i j}, B_{i j} \& D_{i j}$ terms for the laminaete:

$$
\begin{aligned}
& A_{i j}=\sum_{k=1}^{n}\left(Q_{i j}\right)_{k}\left(h_{k}-h_{(k-1)}\right) \\
& B_{i j}=\sum_{k=1}^{n}\left(Q_{i j}\right)_{k}\left(h^{2}{ }_{k}-h^{2}{ }_{(k-1)}\right) / 2 \\
& D_{i j}=\sum_{k=1}^{n}\left(Q_{i j}\right)_{k}\left(h^{3}{ }_{k}-h^{3}{ }_{(k-1)}\right) / 3
\end{aligned}
$$

\section{Laminate stiffness matrix}

Laminaete configuration is symmetric, coupling stiffness $B i j$ will sum to zero.

v. Calculate the corresponding compliance $a_{i j}, b_{i j} \& d_{i j}$ terms by inverting the laminaete stiffness matrix.

vi. Finally, the laminaete equivalent elastic constant in the membrane and bending modes can be calculated having obtained the membrane and bending compliances.

$$
\begin{array}{ll}
E_{x}=1 /\left(t_{11}\right) & \\
\left.E_{y}=1 /\left(t_{22}\right)\right) & \text { Equivalent elastic } \\
G_{x y}=1 /\left(t_{33}\right) & \text { constant } \\
v_{x y}=-a_{12} / a_{11} & \\
v_{y x}=-a_{12} / a_{22} & \\
E_{x}=1 /\left(t_{11}\right) & \\
E_{y}=1 /\left(t_{22}\right) & \text { Equivalent Bending } \\
G_{x y}=1 /\left(t d_{33}\right) & \text { constant } \\
v_{x y}=-d_{12} / d_{11} & \\
v_{y x}=-d_{12} / d_{22} &
\end{array}
$$

\subsubsection{LAMINAETE CONSTITUTIVE EQUATION:}

$$
\left[\frac{M}{N}\right]=\left[\left\langle\frac{A}{B} \mid \frac{B}{D}\right\rangle\right] *\left[\frac{\varepsilon}{\chi}\right]
$$

Where,

M- Moment force in $\mathrm{N} / \mathrm{m}$.

$\mathrm{N}$ - Resultant force in $\mathrm{N} / \mathrm{m}$

A- Extensional stiffness matrix.

B- Bending extensional coupling stiffness matrix.

D- Bending stiffness matrix.

$\varepsilon, \chi-$ Total Strain and curvature.

\subsection{WING CONSTRUCTION}

Wing is a primary structure of the Aircraft. Wings develop the major portion of the lift of a heavierthan-air aircraft. Wing structures carry some of the heavier loads found in the aircraft structure. The particular 
design of a wing depends on many factors, such as the size, weight, speed, rate of climb, and use of the aircraft. The wing must be constructed so that it holds its aerodynamics shape under the extreme stresses of combat maneuvers or wing loading.

\subsubsection{MAJOR PARTS OF THE WING}

Skins (Top \& bottom)
$\quad$ Stringers (Top \& bottom skins)

$\quad \quad$ Spars (Front and rear)

$>\quad$ Ribs

In its simplest form, the wing is a framework made up of spars and ribs. Spars are the main structural members of the wing. They extend from the fuselage to the tip of the wing. The entire load carried by the wing is taken up by the spars. The spars are designed to have great bending strength. Ribs give the wing section its shape, and they transmit the air load from the wing covering to the spars. Ribs extend from the leading edge to the trailing edge of the wing. Most aircraft wings have a removable tip, which streamlines the outer end of the wing.

\subsubsection{WING SKIN}

The skins are the primary structural member stiffened by T-stringers. Skin is fastened or bonded to spars and ribs. The skins are tapered span wise and chord wise, thickened around holes and to produce rib lands. The upper skin panels are substantially thicker than the lower skin panels due to buckling constraints.

\subsection{BUCKLING LOAD ANALYSIS OF COMPOSITE LAMINAETE:}

While flight, the top skin undergo compressive loading which leads to buckling of the skin. It is essential to check the buckling strength of the skin for ultimate load. The stringer stabilizes the skin against buckling with the result that some width of skin acts as part of the stringers and carries loads beyond the general panel buckling stress up to the stringers failure stress. The width of skin which acts as part of the stringer is known as the effective width ' $b$ '. The skin panel length ' $a$ ' and width ' $b$ ' between ribs and stringers respectively is assumed to be a simply supported laminaete under in-plan loading. A panel is to be designed for given inplane loads and two cases of layup sequence. Because of symmetry, there is no extensional-flexural coupling. The pre-buckling deformations are hence purely in-plane. The balance condition requires that for every ply with a positive fiber-orientation angle, there is a corresponding ply with the negative fiber orientation angle. This implies no normal-shear extensional couplings. In addition, the laminaete is assumed specially orthotropic (i.e. there will be no bending-torsion coupling).This is a common assumption in the analysis of balanced symmetric laminaetes for which the bending-torsion coupling terms are usually very small and negligible.

\subsubsection{NORMAL BUCKLING LOAD ANALYSIS}

Under biaxial loading, the laminaete can buckle into $m$ and $n$ half waves in the $x$ and $y$ directions, respectively, when the load amplitude (a factor multiplying the applied loads) reaches a value $\lambda^{(\mathrm{mn})}$, which depends on flexural stiffness $D i j$ and loads $\mathrm{N}_{\mathrm{x}}$ and $\mathrm{N}_{\mathrm{y}}$. $\lambda^{(\mathrm{mn})}=\left\{\pi^{2} x\left[\mathrm{D}_{11}(\mathrm{~m} / \mathrm{a})^{4}+2\left(\mathrm{D}_{12}+2 \mathrm{D}_{66}\right)(\mathrm{m} / \mathrm{a})^{2}(\mathrm{n} / \mathrm{b})^{2}+\mathrm{D}_{22}(\mathrm{n} / \mathrm{b})^{4} /\left\{(\mathrm{m} / \mathrm{a})^{2} \mathrm{~N}_{\mathrm{x}}+(\mathrm{n} / \mathrm{b})^{2} \mathrm{~N}_{\mathrm{y}}\right\}\right.\right.$ The pair $(m, n)$ that yields the smallest value of $\lambda^{(\mathrm{mn})}$, which is the critical buckling load, varies with the loading conditions, total number of plies considered, material, and the plate aspect ratio.

\subsubsection{BUCKLING STRENGTH}

Buckling is a mode of failure characterized generally by an unstable lateral deflection caused by compressive or shear action on the structure element. In composites buckling may take the form not only of conventional general instability and local instability, but also a micro-instability of individual fibers.

\subsubsection{ASSUMPTIONS AND LIMITATIONS OF LINEAR BUCKLING ANALYSIS:}

The following assumptions and limitations apply to linear buckling analysis:

a. The deflections must be small.

b. The element stresses must be elastic.

c. The differential stiffness is supported for the following elements: CONROD, CROD, CTUBE, CBAR, CBEAM, CBEND, CQUAD4, CQUAD8, CTRIA3, CTRIA6, CSHEAR, CHEXA, CPENTA, and CTETRA.

d. A minimum of five grid points per half sine wave (buckled shape) is recommended.

e. The distribution of the internal element forces due to the applied loads remains constant.

f. The follower force effect is not included in the differential stiffness. In other words, the directions, and the magnitudes of the applied forces are assumed to remain constant.

g. The tangent stiffness term due to the follower force effect is not included. This effect is most pronounced for curved structures consisting of thin shells subject to pressure loads. 
h. Offsets should not be used in beam, plate, or shell elements for buckling analysis.

If we are using versions of MSC/NASTRAN earlier than Version 68, the differential stiffness formulation for the CQUAD4 and CTRIA3 may introduce spurious (unreal) modes in thin curved shell structures. For this reason, the design of the differential stiffness for these two elements is improved in Version 68.This new design alleviates this spurious mode problem. This type of spurious mode is rarely encountered.

If we are running versions of MSC/NASTRAN prior to Version 68, you can obtain the same features of the current design by replacing each CQUAD4/CTRIA3 that carries membrane and bending properties with two overlapping CQUAD4s/CTRIA3s-one containing the membrane property and the other containing the bending property

\subsection{INTRODUCTION}

\section{The Finite Element Method}

Finite element method is a numerical analysis technique for obtaining approximate solutions to a wide variety of engineering problems. Although originally developed and applied to the broad field of continuum mechanics. Because of its diversity and flexibility as analysis tool, it is receiving much attention in engineering schools and industry.

In more and more engineering situation today, it is necessary to obtain numerical solutions to problem rather than exact closed from solutions. The resourcefulness of the analyst usually comes to the rescue and provides several alternatives to overcome this dilemma. One possibility is to make simplifying assumption to ignore the difficulties and reduce the problem to one that can be handled sometimes this procedure works but more often than not it leads to series inaccurate or wrong answers. Now that computers are widely available, a more viable alternative is to retain the complexities of the problem and to find an approximate numerical solution.

A finite element model of a problem gives a piecewise approximation to the governing equations'. The basic premise of the finite element method is that a solution region can be analytically modeled or approximated by replacing it with an assemblage of discrete elements since these can be put together in a variety of ways, they can be put together in a variety of ways, and they can be used to represent exceedingly complex shape.

Two features of the finite element method are to be noted,

The piecewise approximation of the physical field on finite elements provides Good precision even with simple approximating functions. Simply increasing the number of elements can achieve increasing precision.

$>$ The locality of the approximation leads to sparse equation systems for a discredited problem. This helps to ease the solution of problems having very large numbers of nodal unknowns. it is not uncommon today to solve Systems. Containing a million primary unknowns.

\subsubsection{SOLUTION PROCEDURE USING FEM SOFTWARE}

All finite element packages require the user to go through these steps in one form to another.

Specifying Geometry- First the geometry of the structure to be analyzed is defined this can be done either by entering the geometric information in the finite element package through the keyboard or mouse or by importing the model from a solid modeler like Pro-ENGINEER.

Specify Element Type and Material Properties- Next, the material properties are defined. In an elastic analysis of an isotropic solid these consist of the Young's modulus and Poisson's ratio of the material.

Mesh the Object-Then the structure is meshed into small elements. This involves defining the types of elements into which the structure will be broken, as well as Specifying how the structure will be subdivided into elements.

Apply Boundary conditions and External Loads- Next, the boundary conditions e.g. .location of supports and the external loads are specified.

Generate a solution- Then the solution is generated based on the previously input parameters.

Post processing- Based on the initial conditions and applied loads, data is returned after a solution is processed. This data can be viewed in a variety of graphs and displays.

Refine the Mesh- Finite element methods are approximate methods and, in General, the accuracy of the approximation increases with the number of elements Used. The number of elements needed for an accurate model depends on the Problem and the specific results to be extracted from it. Thus, in order to judge the number of elements in the object and see if or how the results change.

Interpreting Results- This step is perhaps the most critical step in the entire Knowledge of mechanics to interpret and understand the output of the model. This is critical for applying correct esults to solve real engineering problems and in identifying when modeling mistakes have been made. 
2.1.2 ADVANTAGES OF THE FINITE ELEMENT METHOD

1. Can readily handle complex geometry.

2. Can handle complex analysis types:

$=>$ Vibration $=>$ Transients $=>$ Nonlinear $=>$ Heat transfer $=>$ Fluids

3. Can handle complex loading:

$=>$ Node-based loading (point loads)

=>Element-based loading (pressure, thermal, inertial forces)

$\Rightarrow$ Time or frequency dependent loading.

4. Can handle complex restraints:

$=>$ Indeterminate structures can be analyzed.

5. Can handle bodies comprised of no homogeneous materials:

$=>$ Every element in the model could be assigned a different set of Material properties

6. Can handle bodies comprised of no isotropic materials:

$\Rightarrow$ Orthotropic

$\Rightarrow$ An isotropic

7. Special materials effects are handled:

$\Rightarrow>$ Temperature dependent properties

$=>$ plasticity

$=>$ creep

$=>$ Swelling

8. Special geometric effects can be modeled.

\subsubsection{LIMITATIONS OF THE FINITE ELEMENT METHOD}

1. A general closed-form solution, which would permit one to examine system Response to changes in various parameters, is not produced. The FEM is a applied to an approximation of the mathematical model of a System the source of so-called inherited errors.

2. Experience and judgment are needed in order to construct a good finite Element model

3. A powerful computer and reliable FEM software are essential.

4. Input and output data may be large and tedious to prepare and interpret.

5. Numerical problems:

$\Rightarrow$ Computers only carry a finite number of significant digits.

$=>$ Round off and error accumulation

6. Susceptible to user-introduced modeling errors:

$=>$ Poor choice of element types

$\Rightarrow$ Distorted elements.

$\Rightarrow$ Geometry not adequately modeled.

7. Certain effects not automatically included:

$\Rightarrow$ Buckling

$\Rightarrow$ Large deflections and rotations

=> Material nonlinearities and other nonlinearities.

\subsection{FUNDAMENTALS OF HYPERMESH\&MSC/NASTRAN}

\subsubsection{HYPERMESH}

The pre and post processing of finite element model has been carried out using Hyper Mesh and solving in MSC/NASATRAN. Two Bulk Data entries, MAT8 and PCOMP, are used in the modeling of composite structures. The MAT8 Bulk Data entry defines the material property for an orthotropic material. The PCOMP Bulk Data entry defines the properties of the n-ply composite material laminaete. The thickness, orientation, and the material identification number of each of the individual laminae are provided using this entry.

\subsubsection{MSC/NASTRAN}

NASTRAN stands for NASA STRUCTURAL ANALYSIS program developed by the National Aeronautics and space Administration, USA and upgraded by Mac Neal- Schwendier Corporation under the sponsorship of NASA, based on the known requirements of the aerospace industry for structural analysis.

MSC/NASTRAN is a general purpose finite element analysis computer program MSC/NASTRAN written in FORTRAN contains over one million lines of code.

It is a collection of FORTRAN subroutine programs and designed to perform a specific tasks like ,processing model geometry, assembling matrices, applying constraints, solving matrices, calculating output quantities 

printing the solution and so on. MSC/NASTRAN is capable of solving a wide variety of engineering problems including.

$>\quad$ Linear static analysis

$>\quad$ static analysis with geometric and material non-linearity

$>\quad$ Normal modes and buckling analysis

$>\quad$ Direct and model complex Eigen value analysis

$>\quad$ Direct and model frequency analysis and random response

$>\quad$ Direct and model transient analysis (including response spectrum analysis)

$>\quad$ Linear static analysis and vibration analysis with cyclic symmetry

$>\quad$ Linear and non-linear steady-state heat transfer

$>$ Aero elasticity

Multilevel super elements

$>$ Design sensitivity

$>$ Acoustics

The MSC/NASTRAN library contains more than fifty types of elements which include one-, two- and three dimensional elements, scalar elements, damping elements, axi-symmetric elements, rigid elements, mass elements, fluid elements, etc.

$\begin{array}{ll}> & \text { Large problems capability } \\ > & \text { Multi-level super elements } \\ > & \text { Automatic singularly suppression } \\ > & \text { Automatic re-sequencing } \\ & \text { Data checking and error analysis. }\end{array}$

2.3 FINITE ELEMENT MODELING AND ANALYSIS

2.3.1 GEOMETRY:

A panel of typical wing skin structure between ribs and stringers has been taken. For this 3.6mm thick skin laminaete has the size of $225 \mathrm{~mm}$ X $115 \mathrm{~mm}$.

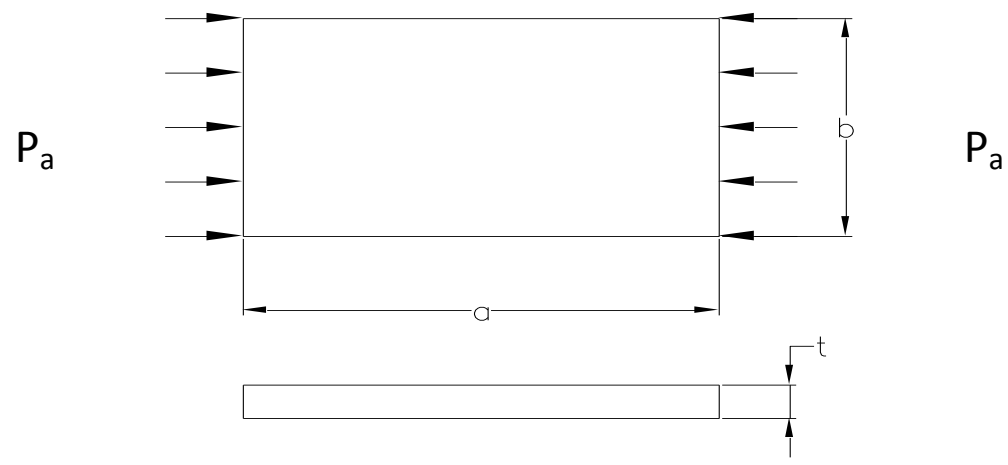

Fig 5.1: Dimension of skin panel

\subsubsection{MATERIAL PROPERTIES:}

Carbon Unidirectional Prepreg 914C T300 has been chosen as a candidate material. The values are shown in the table.

Table 2.1 Physical Properties of the laminae

\begin{tabular}{|c|c|}
\hline $\begin{array}{l}\text { UD Carbon } \\
\text { Properties }\end{array}$ & Prepreg for the cured laminae: Physical \\
\hline Density & thickness of the cured ply, $t$ \\
\hline $1.5 \mathrm{gm} / \mathrm{cc}$ & $0.15 \mathrm{~mm}$ \\
\hline
\end{tabular}




\section{UD Carbon Prepreg for the cured laminae: Elastic properties}

\begin{tabular}{|l|l|l|l|}
\hline $\begin{array}{l}\text { Young's Modulus in fiber } \\
\text { direction, } \mathrm{E}_{11}\end{array}$ & $\begin{array}{l}\text { Young's Modulus in } \\
\text { transverse direction, } \mathrm{E}_{22}\end{array}$ & Shear Modulus, $\mathrm{G}_{12}$ & Poisson's Ratio, $\mu_{11}$ \\
\hline $132 \mathrm{Gpa}$ & $11 \mathrm{Gpa}$ & $5.5 \mathrm{Gpa}$ & 0.33 \\
\hline
\end{tabular}

\subsubsection{ALLOWABLE:}

Table No: 2.3 Design allowable stress of the laminae

\begin{tabular}{|l|l|l|l|l|}
\hline UD Carbon \&Epoxy laminae : Design allowable \\
\hline $\begin{array}{l}\text { Tensile Stress in } \\
\text { fiber direction, } \mathrm{S}_{\mathrm{XT}}\end{array}$ & $\begin{array}{l}\text { Compressive } \\
\text { Stress in fiber } \\
\text { direction, } \mathrm{S}_{\mathrm{XC}}\end{array}$ & $\begin{array}{l}\text { Tensile Stress in } \\
\text { transverse } \\
\text { direction, } \mathrm{S}_{\mathrm{YT}}\end{array}$ & $\begin{array}{l}\text { Compressive } \\
\text { Stress in transverse } \\
\text { direction, } \mathrm{S}_{\mathrm{YT}}\end{array}$ & Shear Stress $\tau_{\mathrm{XY}}$ \\
\hline 432Mpa & $506 \mathrm{Mpa}$ & $25 \mathrm{Mpa}$ & $25 \mathrm{Mpa}$ & $36 \mathrm{Mpa}$ \\
\hline
\end{tabular}

\subsubsection{BOUNDARY CONDITIONS:}

The edges parallel to the loading direction are constrained in all translational degrees of freedom. The loading edges are constrained only in z-direction.

\subsubsection{LAY UP SEQUENCE:}

Following layup sequence have been used for these two cases.

Case-I: $\left[+45^{\circ},-45^{\circ},+45^{\circ},-45^{\circ}, 0^{\circ}, 90^{\circ},+45^{\circ},-45^{\circ},+45^{\circ},-45^{\circ}, 0^{\circ}, 90^{\circ}\right]_{\mathrm{s}}$

Case-II: $\left[+45^{\circ},-45^{\circ}, 0^{\circ}, 90^{\circ}, 0^{\circ}, 90^{\circ}, 0^{\circ}, 90^{\circ}, 0^{\circ}, 90^{\circ},+45^{\circ},-45^{\circ}\right]$

2.3.6 FE MODELING:

Finite element model of skin panel with loading and boundary condition is shown in fig 5.2.

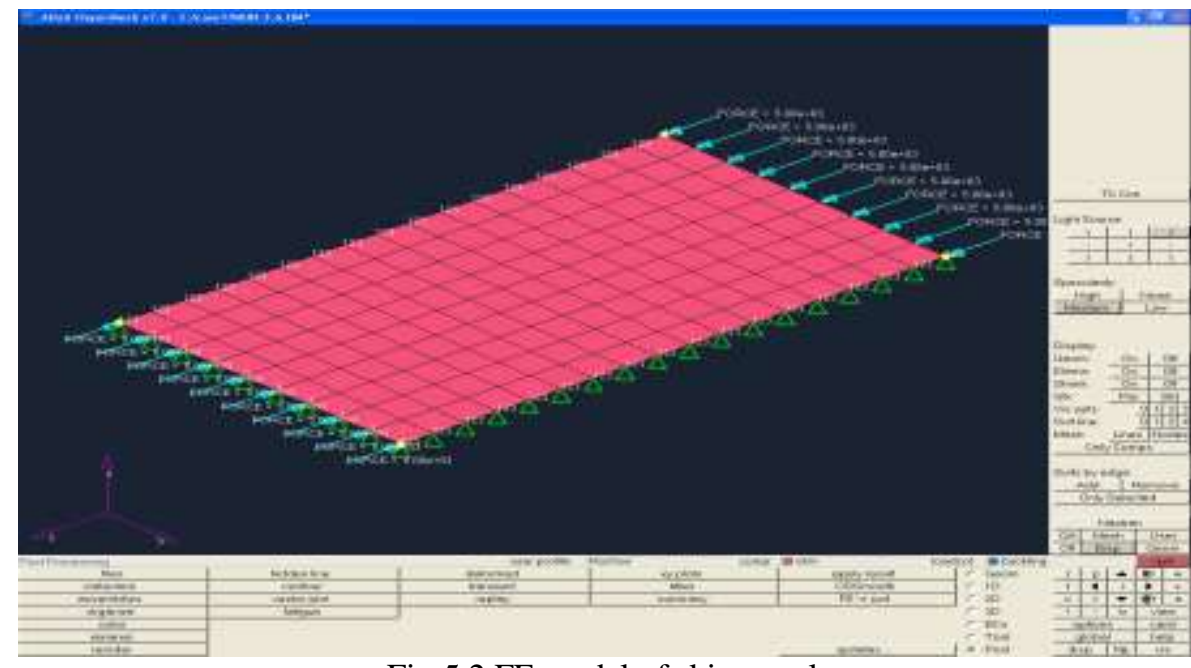

Fig 5.2 FE model of skin panel

The preprocessing of finite element model has been carried out using Hyper Mesh. Two Bulk Data entries, MAT8 and PCOMP, are used in the modeling of composite structures. The MAT8 Bulk Data entry defines the material property for an orthotropic material. The PCOMP Bulk Data entry defines the properties of the n-ply composite material laminaete. The thickness, orientation, and the material identification number of each of the individual laminae are provided using this entry.

\subsubsection{MESHING:}

The procedure for generating a mesh of nodes and elements Consists of three main steps:

- Set the element attributes

- Set mesh control, Hyper mesh offers a large number of mesh which we can choose from to suit our needs.

- Generate the mesh

The second step, setting mesh controls, is not always necessary because the mesh controls are appropriate for many models. If no controls are specified, the program will use the default settings to 
produce a free mesh. As an alternative, we can use the smart size feature to produce a better quality free mesh.

Before meshing the model, and even before building the model, it is important to think about whether a free mesh or a mapped mesh is appropriate for the analysis. A free mesh has no restrictions in terms of element shapes, and has no specified pattern applied to it.

Compared to a free mesh, a mapped mesh is restricted in terms of the element shape it contains and the pattern of the mesh. A mapped area mesh contains either only quadrilateral or only triangular elements, while a mapped mesh typically has a regular pattern, with rows of elements. If we want this type of mesh we must build the geometry as a series of fairly regular volumes and/or areas that can accept a mapped mesh. Before we generate a mesh of nodes and elements, we must first define the appropriate element attributes. That is we must specify the following:

- Element type

- Material properties

- Element Co-ordinate system

\subsubsection{APPLIED LOADS:}

The in-plane compressive load has been determined from an actual aircraft critical load cases on wing at various flight conditions such as take off, landing, maneuvering, etc. and is applied on simply supported laminaeted skin. The compressive load is found to be $50000 \mathrm{~N}$.

\subsubsection{SOLVER:}

Processing stage involves computation of parameters for memory/file management, computation of element matrices and vectors, forming global matrices and vectors, enforcing SPC, MPC and finally solving the governing matrix equation. The software package MSC/NASTRAN has been used as the processor.

\subsubsection{POST-PROCESSING:}

Post-processing stage deals with the presentation of results. Typically the deformed mesh configuration, mode shapes and stress distributions are computed and displayed at this stage. They can be printed/plotted. The results of the finite element analysis are also presented in the form of graphs, charts and tables for the easy interpretation of the results. Here, the post processing has been done using MSC/XL and FEMAP.

STACKING LAYUP SEQUENCE OF LAMINAETE

\section{CALCULATIONS} $\left(+45^{\circ},-45^{\circ},+45^{\circ},-45^{\circ}, 0^{\circ}, 90^{\circ},+45^{\circ},-45^{\circ},+45^{\circ},-45^{\circ}, 0^{\circ}, 90^{\circ}\right) \mathrm{s}$

3.1. Calculation to find the Equivalent properties of skin panel for case-i

Elastic properties of laminae is given as

Young's Modulus in fiber direction, $\mathrm{E}_{11}=132 \mathrm{Gpa}$

Young's Modulus in transverse direction, $\mathrm{E}_{22}=11 \mathrm{Gpa}$

Shear Modulus, $\mathrm{G}_{12=} 5.5 \mathrm{Gp}$

Poisson's Ratio, $V_{12}=0.3$

3.1.1 Find the Transformed reduced Stiffness matrix:

i) Determination of reduced stiffness matrix [Q]

$$
\begin{aligned}
\mathrm{Q}_{11} & =\mathrm{E}_{11} /\left(1-\mathrm{V}_{12} \mathrm{~V}_{21}\right) \\
\mathrm{Q}_{22} & =\mathrm{E}_{22} /\left(1-\mathrm{V}_{12} \mathrm{~V}_{21}\right) \\
\mathrm{Q}_{12} & =\mathrm{Q}_{21}=\mathrm{V}_{12} \mathrm{X} \mathrm{E}_{22} /\left(1-\mathrm{V}_{12} \mathrm{~V}_{21}\right) \\
\mathrm{Q}_{66} & =\mathrm{G}_{12} \\
\mathrm{~V}_{21} & =\mathrm{E}_{22} \mathrm{X}_{12} / \mathrm{E}_{11} \\
& =11 \mathrm{x} .33 / 132 \\
& =0.0275 \\
\mathrm{Q}_{11} & =\mathrm{E}_{11} /\left(1-\mathrm{V}_{12} \mathrm{~V}_{21}\right) \\
\mathrm{Q}_{11} & =132 /(1-0.33 \times .0275) \\
& =133.208 \mathrm{GPa} \\
\mathrm{Q}_{22} & =11 /(1-0.33 \mathrm{x} 0.0275) \\
& =3.663 \mathrm{GPa} \\
\mathrm{Q}_{66} & =5.5 \mathrm{GPa}
\end{aligned}
$$

$$
\begin{aligned}
\mathrm{U}_{2} & =\left(\mathrm{Q}_{11}-\mathrm{Q}_{22}\right) / 2 \\
& =(133.208-11.1) / 2 \\
& =61.054 \mathrm{GPa} . \\
\mathrm{U}_{3}= & \left(\mathrm{Q}_{11}+\mathrm{Q}_{22}-2 \mathrm{Q}_{12}-4 \mathrm{Q}_{66}\right) / 8 \\
& =(133.208+11.1+2 \times 3.663-4 \times 5.5) / 8 \\
& =14.372 \mathrm{GPa} . \\
\mathrm{U}_{4} & =\left(\mathrm{Q}_{11}+\mathrm{Q}_{22}+6 \mathrm{Q}_{12}-4 \mathrm{Q}_{66}\right) / 8 \\
& =(133.208+11.1+6 \times 3.663-4 \times 5.5) / 8 \\
& =18.035 \mathrm{GPa} . \\
\mathrm{U}_{5} & =\left(\mathrm{U}_{1}-\mathrm{U}_{4}\right) / 2 \\
& =19.873 \mathrm{GPa} .
\end{aligned}
$$

ii) Angle invariant stiffness of a laminae

$$
\begin{aligned}
\mathrm{U}_{1} & =\left(3 \mathrm{Q}_{11}+3 \mathrm{Q}_{22}+2 \mathrm{Q}_{12}+4 \mathrm{Q}_{66}\right) / 8 \\
& =(3 \times 133.208+3 \times 11.1+2 \times 3.663+4 \times 5.5) / 8 \\
& =57.781 \mathrm{GPa} .
\end{aligned}
$$

iii) Elements of transformed reduced Stiffness matrix for $\theta=45^{\circ}$

$$
\begin{aligned}
\overline{\mathrm{Q}}_{11}=\mathrm{U}_{1} & +\mathrm{U}_{2} \operatorname{Cos} 2 \theta+\mathrm{U}_{3} \operatorname{Cos} 4 \theta \\
& = \\
& 57.781+61.054 \times \operatorname{Cos} 90^{\circ}+14.372 \times \operatorname{Cos} 180^{\circ} \\
& =43.409 \mathrm{GPa} .
\end{aligned}
$$


Finite Element Modeling And Analysis Of Skin Panel Based On The Fiber Orientation And Stacking
$\overline{\mathrm{Q}_{21}}=\mathrm{Q}_{12}=\mathrm{U}_{4}-\mathrm{U}_{3} \operatorname{Cos}\left(-180^{\circ}\right)$
$=18.03-14.372 \times(-1)$
$=32.407 \mathrm{GPa}$.
$\overline{Q_{16}}=\left(\mathrm{U}_{2} \operatorname{Sin} 2 \theta\right) / 2+\mathrm{U}_{3} \operatorname{Sin} 4 \theta$
$=(61.054 \times 1) / 2+14.372 * 0$
$=30.527 \mathrm{Gpa}$.
$\overline{\mathrm{Q}}_{66}=\mathrm{U}_{5}-\mathrm{U}_{3} \operatorname{Cos} 4 \theta$
$=19.873-14.372 \times(-1)$

$$
\begin{aligned}
\overline{\mathrm{Q}}_{22} & =\mathrm{U}_{1}-\mathrm{U}_{2} \operatorname{Cos} 2 \theta+\mathrm{U}_{3} \operatorname{Cos} 4 \theta \\
& =57.781-0+14.37(-1) \\
& =43.409 \mathrm{Gpa} \\
\overline{\mathrm{Q}}_{26} & =\left(\mathrm{U}_{2} \operatorname{Sin} 2 \theta\right) / 2-\mathrm{U}_{3} \operatorname{Sin} 4 \theta \\
& =61.054 / 2+0 \\
& =30.527 \mathrm{Gpa} .
\end{aligned}
$$

Transformed reduced Stiffness matrix for each of the four plies is

i) Stiffness matrix for $\theta=-45^{\circ}$ laminae

$$
\begin{aligned}
{\left[\overline{\mathrm{Q}}_{45}{ }_{45}=\right.} & \left(\begin{array}{lll}
\overline{\mathrm{Q}}_{11} & \overline{\mathrm{Q}}_{12} & \overline{\mathrm{Q}}_{16} \\
\overline{\mathrm{Q}}_{21} & \overline{\mathrm{Q}}_{22} & \overline{\mathrm{Q}}_{26} \\
\overline{\mathrm{Q}}_{16} & \overline{\mathrm{Q}}_{26} & \overline{\mathrm{Q}}_{66}
\end{array}\right) \\
= & \left(\begin{array}{lll}
43.409 & 32.407 & 30.527 \\
32.409 & 43.409 & 30.572 \\
30.527 & 30.527 & 34.245
\end{array}\right)
\end{aligned}
$$

ii) Stiffness matrix for $\theta=-45^{\circ}$ laminae

$$
[\bar{Q}]_{-45^{\circ}}=\left(\begin{array}{rrr}
43.409 & 32.407 & -30.527 \\
32.407 & 43.409 & -30.572 \\
-30.572 & -30.527 & 34.245
\end{array}\right)
$$

iii) Stiffness matrix for $\theta=90^{\circ}$ laminae

$$
[\bar{Q}]_{90^{\circ}}=\left(\begin{array}{ccc}
11.099 & 3.663 & 0 \\
3.663 & 133.207 & 0 \\
0 & 0 & 5.507
\end{array}\right)
$$


iv) Stiffness matrix for $\theta=0^{\circ}$ laminae

$$
[\bar{Q}]_{0^{\circ}}=\left(\begin{array}{ccc}
133.207 & 3.663 & 0 \\
3.663 & 11.1 & 0 \\
0 & 0 & 5.507
\end{array}\right)
$$

\subsubsection{Determination of Bending matrix $\left[D_{\mathrm{mn}}\right]$ of laminaete ,}

The total thickness of the laminaete is $3.6 \mathrm{~mm}$.the midplane is $\mathrm{h}=1.8 \mathrm{~mm}$ from the top and bottom of the laminaete. Thus, the locations of the ply surfaces are

$\left[\mathrm{h}_{24}=-\mathrm{h}_{0}=1.8 \mathrm{~mm}, \mathrm{~h}_{23}=-\mathrm{h}_{1}=1.65 \mathrm{~mm}, \mathrm{~h}_{22}=-\mathrm{h}_{2}=1.5 \mathrm{~mm}, \mathrm{~h}_{21}=-\mathrm{h}_{3}=1.35 \mathrm{~mm}, \mathrm{~h}_{20}=-\mathrm{h}_{4}=1.2 \mathrm{~mm}, \mathrm{~h}_{19}=-\mathrm{h}_{5}=1.05 \mathrm{~mm}, \mathrm{~h}_{18}=\right.$ $\left.-\mathrm{h}_{6}=0.9 \mathrm{~mm}, \mathrm{~h}_{16}=-\mathrm{h}_{7}=0.75 \mathrm{~mm}, \mathrm{~h}_{15}=\mathrm{h}_{8}=0.6 \mathrm{~mm}, \mathrm{~h}_{14}=-\mathrm{h}_{9}=0.45 \mathrm{~mm}, \mathrm{~h}_{13}=-\mathrm{h}_{10}=0.3 \mathrm{~mm}, \mathrm{~h}_{12}=-\mathrm{h}_{11}=0.15 \mathrm{~mm}\right]$

The Bending stiffness matrix equation is

$$
D_{i j}=\sum_{k=1}^{n}\left(Q_{i j}\right)_{k}\left(h^{3}{ }_{k}-h^{3}(k-1)\right) / 3
$$

Where

$\mathrm{n}=$ total no. of laminas in the laminaete

$\mathrm{h}_{\mathrm{j}}=$ Distance from mid plane to the bottom of the $\mathrm{j}^{\text {th }}$ laminae

$\mathrm{h}_{\mathrm{j}-1}=$ Distance from mid plane to the top of the $\mathrm{j}^{\text {th }}$ laminae

$\mathrm{D}_{\mathrm{mn}}=(1 / 3) \times\left\{\left(\overline{\mathrm{Q}}_{\mathrm{mn}}\right)_{45^{\circ}} \times\left[\mathrm{h}^{3}{ }_{1}-\mathrm{h}^{3}{ }_{0}+\mathrm{h}^{3}{ }_{23}-\mathrm{h}^{3}{ }_{23}+\mathrm{h}^{3}{ }_{3}-\mathrm{h}^{3}{ }_{2}+\mathrm{h}^{3}{ }_{22}-\mathrm{h}^{3}{ }_{21}+\mathrm{h}^{3}{ }_{7}-\mathrm{h}^{3}{ }_{6}+\mathrm{h}^{3}{ }_{18}-\mathrm{h}^{3}{ }_{17}+\mathrm{h}^{3}{ }_{9}-\mathrm{h}^{3}{ }^{3}+\mathrm{h}^{3}{ }_{16}-\mathrm{h}^{3}{ }_{15}\right]+\left(\overline{\mathrm{Q}}_{\mathrm{mn}}\right)_{-}\right.$ ${ }_{45^{\circ}} \mathrm{x}\left[\mathrm{h}^{3}{ }^{-} \mathrm{h}^{3}{ }_{1}+\mathrm{h}^{3}{ }_{23^{-}} \mathrm{h}^{3}{ }_{22}+\mathrm{h}^{3}{ }_{4}-\mathrm{h}^{3}{ }_{3}+\mathrm{h}_{21}^{3}{ }^{3} \mathrm{~h}^{3}{ }_{20}+\mathrm{h}^{3}{ }_{8^{-}} \mathrm{h}^{3}{ }_{7}+\mathrm{h}^{3}{ }_{17}-\mathrm{h}^{3}{ }_{16}+\mathrm{h}^{3}{ }_{10} \mathrm{~h}^{3}{ }_{9}+\mathrm{h}^{3}{ }_{15^{-}} \mathrm{h}^{3}{ }_{14}\right]+\left(\overline{\mathrm{Q}}_{\mathrm{mn}}\right)_{0^{\circ}} \mathrm{x}\left[\mathrm{h}^{3}{ }_{5}-\mathrm{h}^{3}{ }_{4}\right.$ $\left.\left.+\mathrm{h}^{3}{ }_{20^{-}} \mathrm{h}^{3}{ }_{19}+\mathrm{h}^{3}{ }_{11}-\mathrm{h}^{3}{ }_{10}+\mathrm{h}^{3}{ }_{14^{-}} \mathrm{h}^{3}{ }_{13}\right]+\left(\overline{\mathrm{Q}}_{\mathrm{mn}}\right)_{90^{\circ}} \mathrm{x}\left[\mathrm{h}^{3}{ }^{3}-\mathrm{h}^{3}{ }_{5}+\mathrm{h}^{3}{ }_{19}-\mathrm{h}^{3}{ }_{18}+\mathrm{h}^{3}{ }_{12}-\mathrm{h}^{3}{ }_{11}+\mathrm{h}^{3}{ }_{13^{-}}-\mathrm{h}^{3}{ }_{12}\right]\right\}$

$\left[\mathrm{D}_{\mathrm{mn}}\right]_{45^{\circ}}=\left\{(1.34+1.34+0.9146+0.9146+0.307+0.307+0.124+0.124) \times\left(\overline{\mathrm{Q}}_{\mathrm{mn}}\right)_{45^{\circ}}\right\} / 3$

$$
=1.791 \times\left(\overline{\mathrm{Q}}_{\mathrm{mn}}\right)_{45^{\circ}}
$$

$\left[\mathrm{D}_{\mathrm{mn}}\right]_{-45^{\circ}}=\left\{(1.11+1.11+0.732+0.732+0.205+0.205+0.064+0.064) \times\left(\overline{\mathrm{Q}}_{\mathrm{mn}}\right)_{45^{\circ}}\right\} / 3$

$$
=1.419 x\left(\overline{\mathrm{Q}}_{\mathrm{mn}}\right)_{-45^{\circ}}
$$

$\left[\mathrm{D}_{\mathrm{mn}}\right]_{0^{\circ}}=(1 / 3)\left\{(0.570+0.570+0.0236+0.0236) \times\left(\overline{\mathrm{Q}}_{\mathrm{mr}}\right)_{0^{\circ}}\right\}$

$$
=0.3959 \times\left(\overline{\mathrm{Q}}_{\mathrm{mn}}\right)_{0^{\circ}}
$$

$\left[\mathrm{D}_{\mathrm{mn}}\right]_{90^{\circ}}=(1 / 3)\left\{(0.428+0.428+0.0033+0.0033) \times\left(\overline{\mathrm{Q}}_{\mathrm{mn}}\right)_{90^{\circ}}\right\}$

$=0.288 \times\left(\overline{\mathrm{Q}}_{\mathrm{mn}}\right)_{90^{\circ}}$

$\left[\mathrm{D}_{\mathrm{mn}}\right]=1.791 \times\left(\overline{\mathrm{Q}}_{\mathrm{mn}}\right)_{45^{\circ}+} 1.419 \times\left(\overline{\mathrm{Q}}_{\mathrm{mn}}\right)_{-45^{\circ}+} 0.3959 \times\left(\overline{\mathrm{Q}}_{\mathrm{mn}}\right)_{0^{\circ}+} 0.288 \mathrm{x}\left(\overline{\mathrm{Q}}_{\mathrm{mn}}\right)_{90^{\circ}}$

$D_{m n}=1.791 \times\left(\begin{array}{lll}43.409 & 32.407 & 30.527 \\ 32.409 & 43.409 & 30.572 \\ 30.527 & 30.527 & 34.245\end{array}\right)+1.419 x \quad\left[\begin{array}{rrr}43.409 & 32.407 & -30.527 \\ 32.407 & 43.409 & -30.572 \\ -30.572 & -30.527 & 34.245\end{array}\right.$


$+0.288 x$

Which is gives

\subsubsection{Determination of buckling strength of laminaete}

The buckling strength of the laminaete is defined as:

$$
\overline{N_{x}}=\left(\pi^{2} / \mathrm{a}^{2} \mathrm{~m}^{2}\right) \times\left[\mathrm{D}_{11} \mathrm{~m}^{4}+2\left(\mathrm{D}_{12}+2 \mathrm{D}_{66}\right)(\mathrm{mnR})^{2}+\mathrm{D}_{22}(\mathrm{nR})^{4}\right]
$$

Where,

m \& $\mathrm{n}$ buckling mode shape parameter a \& $b$ length and width of the panel.

$$
\begin{aligned}
& \overline{N_{x}}=\left\{\pi^{2}\left[195+2(106+2 \mathrm{X} 113) \mathrm{X}(1 \times 1.95)^{2}+\left(182 \mathrm{X}(1.95)^{4}\right)\right]\right\} / 0.225^{2} \\
& \quad=1043445 \mathrm{~N} / \mathrm{m}
\end{aligned}
$$

For width of $0.115 \mathrm{~m}$

$$
\begin{aligned}
& 0.115 \times 1043445=119996 \mathrm{~N} \\
& \text { Buckling strength }=119996 \mathrm{~N} \\
& \text { Buckling factor } \lambda_{1}=119996 \mathrm{~N} / 50000 \mathrm{~N} \\
& \text { Buckling factor } \lambda_{1=2.3}
\end{aligned}
$$

\subsubsection{Determination of displacement of the laminaete:}

The displacement of the laminaete is defined as:

$$
\mathrm{W}_{\mathrm{mn}}=\mathrm{a}^{4} \mathrm{x} \mathrm{q}_{\mathrm{mn}} /\left\{\pi^{4}\left[\mathrm{D}_{11} \mathrm{~m}^{4}+2\left(\mathrm{D}_{12}+2 \mathrm{D}_{66}\right)(\mathrm{mnR})^{2}+\mathrm{D}_{22}(\mathrm{nR})^{4}\right\}\right.
$$

Where

$$
\begin{aligned}
& \mathrm{a}, \mathrm{b} \text { size of the laminaete } \\
& \mathrm{a}=225 \mathrm{~mm}, \mathrm{~b}=115 \mathrm{~mm} \\
& \mathrm{q}_{0}=\text { applied load }(50 \mathrm{KN}) \\
& \mathrm{q}_{\mathrm{mn}}=16 \times \mathrm{q}_{0} /\left(\pi^{2} \mathrm{mn}\right) \\
& \mathrm{R}=\mathrm{a} / \mathrm{b}=1.95 \\
& \mathrm{~W}_{\mathrm{mn}}=\left(0.225^{4} \times 16 \times 50000\right) /\left\{\pi^{6}\left[195+2(106+2 \times 113) \times 1.95^{2}+182 \times 1.94^{4}\right]\right\} \\
& =0.00039 \mathrm{~mm} \\
& \mathrm{~W}_{\mathrm{mn}}=0.39 \mathrm{~m}
\end{aligned}
$$



3.1.5 Determination of Extensional stiffness matrix:

Where,

$$
A_{i j}=\sum_{k=1}^{n}\left(Q_{i j}\right)_{k}\left(h_{k}-h_{(k-1)}\right)
$$

$$
\begin{aligned}
& \mathrm{h}_{\mathrm{k}} \text { - thickness of laminaete }=3.6 \mathrm{~mm} \quad, \mathrm{n}-\text { No. of plies }
\end{aligned}
$$

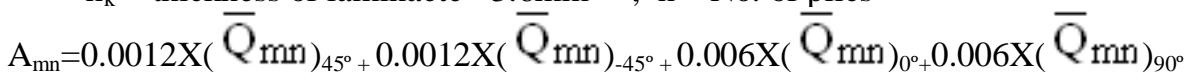

$$
\begin{aligned}
& \mathrm{A}_{\mathrm{mn}}=0.002+\left(\begin{array}{rrr}
43.409 & 32.407 & 30.527 \\
32.409 & 43.409 & 30.572 \\
30.527 & 30.527 & 34.245
\end{array}\right)_{+0.002 \mathrm{x}} \\
& +0.006 \times\left(\begin{array}{ccc}
133.207 & 3.663 & 0 \\
3.663 & 11.1 & 0 \\
0 & 0 & 5.507
\end{array}\right)\left(\begin{array}{ccc}
11.099 & 3.663 & 0 \\
3.663 & 133.207 & 0 \\
0 & 0 & 5.507
\end{array}\right) \\
& A_{m n}=\left(\begin{array}{ccc}
190.75 & 82.17 & 0 \\
82.17 & 190.75 & 0 \\
0 & 0 & 88.78
\end{array}\right)
\end{aligned}
$$

The Extensional compliance matrix as

$$
\mathrm{A}^{-1}=\left(\begin{array}{lll}
\mathrm{a}_{11} & \mathrm{a}_{12} & \mathrm{a}_{16} \\
\mathrm{a}_{12} & \mathrm{a}_{22} & \mathrm{a}_{26} \\
\mathrm{a}_{16} & \mathrm{a}_{26} & \mathrm{a}_{66}
\end{array}\right)
$$




$$
\mathrm{A}^{-1}=
$$

3.1.6 Determination of Equivalent membrane elastic constant of the laminaete;

The in-plane engineering constants are formed as follows

$$
\begin{aligned}
& \mathrm{E}_{\mathrm{x}}=1 /\left(\begin{array}{lll}
\mathrm{tr}_{11} & \mathrm{a}_{11}
\end{array}\right) \\
& \mathrm{E}_{\mathrm{y}}=1 /\left(\begin{array}{lll}
\mathrm{t} & \mathrm{x} & \mathrm{a}_{22}
\end{array}\right) \\
& \mathrm{G}_{\mathrm{xy}}=1 /\left(\begin{array}{lll}
\mathrm{t} & \mathrm{x} & \mathrm{a}_{66}
\end{array}\right)
\end{aligned}
$$

i) Effective in-plane longitudinal modulus $\left(\mathrm{E}_{\mathrm{x}}\right)$

$$
\begin{aligned}
\mathrm{E}_{\mathrm{x}} & =1 /\left(\mathrm{t} \mathrm{x} \mathrm{a}_{11}\right) \\
& =1 /(0.0036 \times 6.5) \\
& =42.73 \mathrm{GPa} .
\end{aligned}
$$

ii) Effective in-plane transverse modulus $\left(\mathrm{E}_{\mathrm{y}}\right)$

$$
\begin{aligned}
\mathrm{E}_{\mathrm{y}} & =1 /\left(\mathrm{t} \mathrm{x} \mathrm{a} \mathrm{a}_{22}\right) \\
& =1 /(0.0036 \times 6.5) \\
& =42.73 \mathrm{GPa} .
\end{aligned}
$$

iii) Effective in-plane shear modulus $\left(\mathrm{G}_{\mathrm{xy}}\right)$

$$
\begin{aligned}
\mathrm{G}_{\mathrm{xy}} & =1 /\left(\mathrm{t} \mathrm{x} \mathrm{a}_{66}\right) \\
& =1 /(0.0036 \times 11.25) \\
& =24.7 \mathrm{GPa} .
\end{aligned}
$$

iv) Effective in-plane Poisson ratio $\left(\mathrm{v}_{\mathrm{xy}}\right)$

$$
\begin{aligned}
& v_{y y}=-a_{12} / a_{11} \\
= & (2.79 / 6.46) \\
= & 0.43
\end{aligned}
$$

Table 3.1Equivalent properties of the laminaete

\begin{tabular}{|l|l|l|l|}
\hline $\begin{array}{l}\text { Modulus Ex } \\
\text { GPa }\end{array}$ & $\begin{array}{l}\text { Modulus E } \\
\text { GPa }\end{array}$ & $\begin{array}{l}\text { Shear Modulus } \\
\mathbf{G}_{\mathrm{xy}}, \text { in GPa }\end{array}$ & $\begin{array}{l}\text { Poisson's Ratio } \\
\boldsymbol{\mu}_{\mathrm{xy}}\end{array}$ \\
\hline 42.7 & 42.7 & $\mathbf{2 4 . 7}$ & $\mathbf{0 . 4 3}$ \\
\hline
\end{tabular}

\subsection{Analysis Results:}

\section{RESULTS AND DISCUSSION}

The stiffness values of the skin panel for two cases having different layup sequence are presented in table 4.1. The analysis results of displacement, Normal stress, shear stress and buckling displacement contour are shown in Fig 4.1 to 4.4. The values are shown in the table 4.2.

Table 4.1 stiffness values of skin panel

\begin{tabular}{|c|c|c|c|}
\hline Modulus Ex, in GPa & Modulus E $\mathrm{y}_{\mathrm{y}}$, in GPa & $\begin{array}{c}\text { Shear Modulus } \mathrm{G}_{\mathrm{xy}}, \\
\text { in GPa }\end{array}$ & Poisson's Ratio $\mu_{\mathrm{xy}}$ \\
\hline 42.7 & 42.7 & 24.7 & 0.43 \\
\hline 65.2 & 65.2 & 12 & 0.18 \\
\hline
\end{tabular}

Table 4.2 Analysis results of displacement, Normal stress, shear stress and buckling displacement of the skin panel

\begin{tabular}{|c|c|c|c|}
\hline $\begin{array}{c}\text { Displacement, } \\
\mathrm{mm}\end{array}$ & Normal Stress, MPa & Shear stress, MPa & Buckling Factor \\
\hline 0.140 & 37.2 & 74.5 & 2.07 \\
\hline
\end{tabular}

4.1.1Analysis results of laminaete for layup sequence $\left[+45^{\circ},-45^{\circ},+45^{\circ},-45^{\circ}, 0^{\circ}, 90^{\circ},+45^{\circ},-45^{\circ},+45^{\circ},-45^{\circ}, 0^{\circ}, 90^{\circ}\right]_{\mathrm{s}}$ 


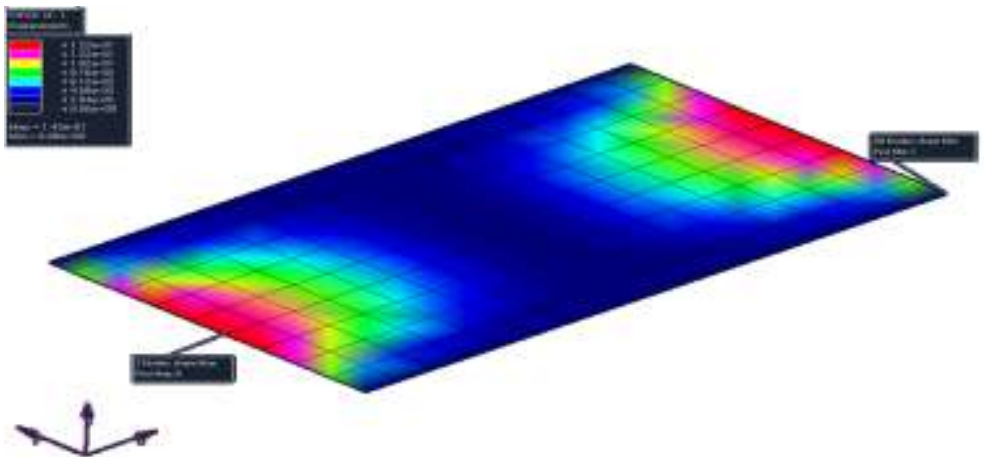

Fig 4.1 Displacement contour of the laminaete
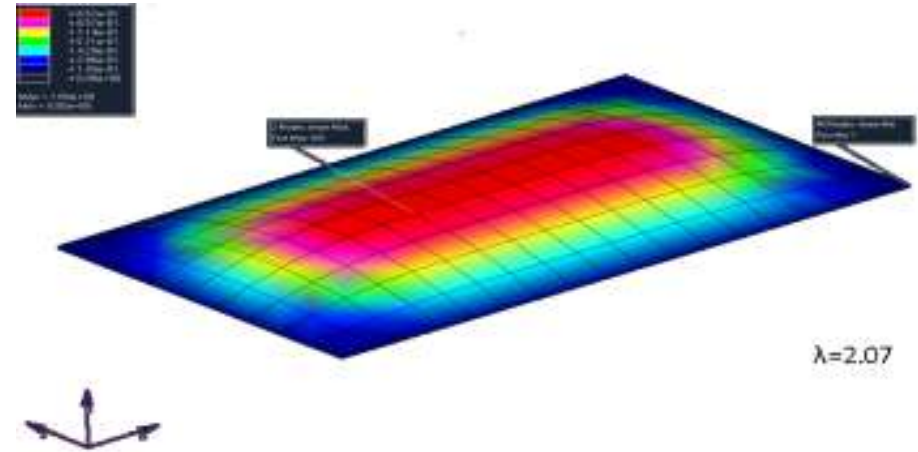

Fig 4.2 Buckling Displacement contour of the laminaete

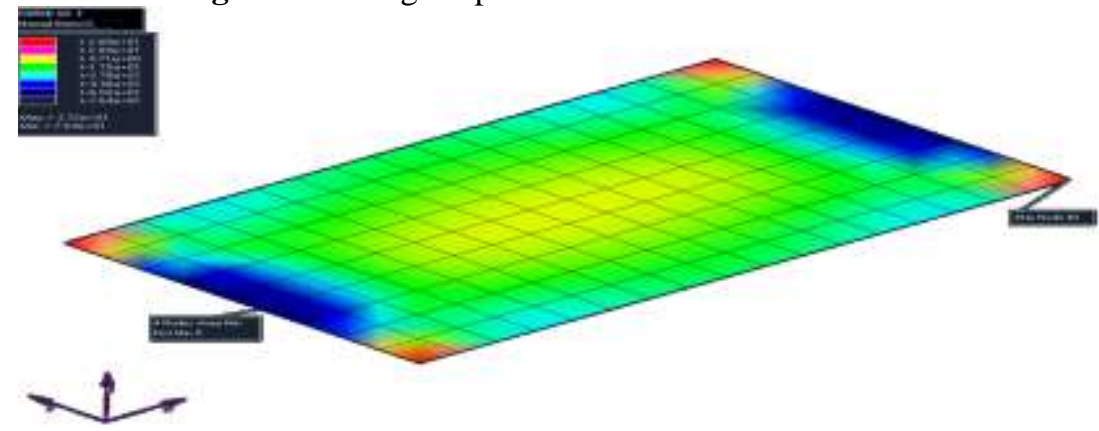

Fig 4.3 Normal Stress contour of the laminaete
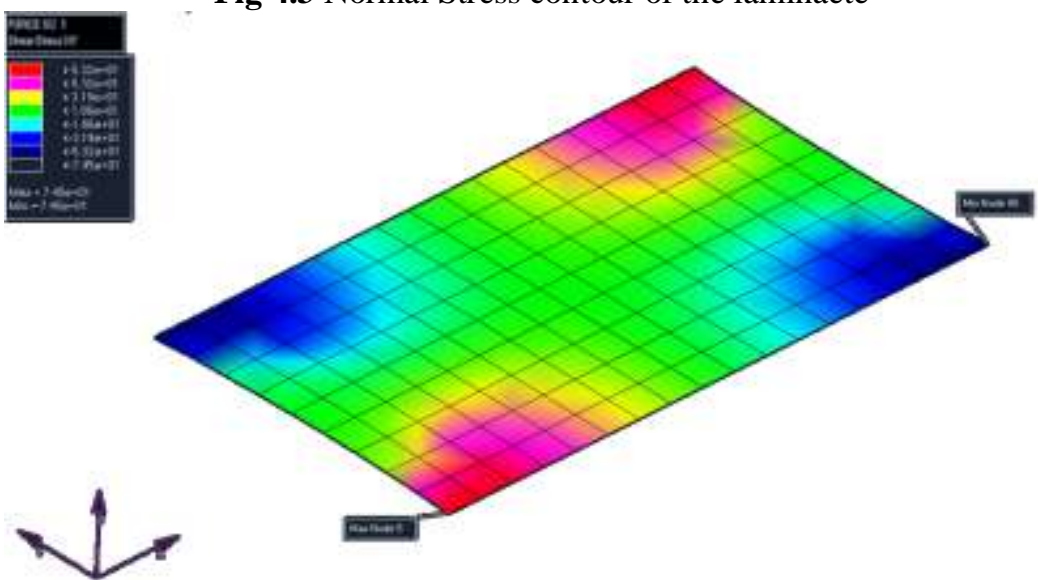

Fig 4.4 Shear Stress contour of the laminaete 


\section{CONCLUSION}

The stiffness values of the laminaete for the two cases have been calculated. The detail FE modeling and analysis results of the laminaete are presented for two cases. There are significant variations in the results among those two cases. The study has been revealed that the laminaete properties and strength is based on the fiber orientation and stacking sequence.

\subsection{Further work:}

It is vitally important to understand the behavior of the laminaete from which we can tailor the laminaete properties and strength. This study can extensively be utilized while designing the various structural members.

\section{Reference}

[1] Jones Mechanics of Composite Materials George Voyiadjis Peter I.Kat tan - Mechanics of Composite Materials.

[2] P.K.Mallick- Fiber-Reinforced composite Buckling strength of uniaxially compressed orthogonally stiffened plates- József Farkas Ashton, J.E., J.C.Halpin\&P.H.Petit, PrimeronCompositeMaterials.

[3] Harris, B., Engineering Composite Materials, the Institute of Metals.

[4] Hull, D. and T.W. Clyne, an Introduction to Composites Material.

[5] Jones, R.M., Mechanics of Composite Materials, McGraw-Hill, New York, www.google.co.in

[6] Mechanical properties of PP/jute and Glass Fibers composites: The statistical Investigation by amirhossein estandirai 